\title{
Measuring Vehicle Speeds, Compliance Rates, and Braking Reaction Times at Level Crossings Using Fixed and Moving Driving Simulators
}

\author{
Inhi Kim ${ }^{a}$, Khaled Shaaban ${ }^{b *}$ \\ ${ }^{a}$ Kongju National University, Chungcheongnam-do, South Korea \\ ${ }^{b}$ Utah Valley University, Orem, Utah, United States, 84058
}

\begin{abstract}
Driving simulators are used for many applications including traffic safety. There are several types of driving simulators available for researchers and engineers. This study aims to compare fixed and moving driving simulators in assessing driving behaviors at railway crossings equipped with either typical stop signs or in-vehicle audio safety system. Data used in the comparison included vehicle speed profiles, compliance rates, and braking reaction times. It was found that compliance rates were similar whereas speed profiles and breaking reaction times were slightly different. As the results of the desktop simulator had previously been compared with those from the data collected in the field, the comparison of results between the two simulators reported here can serve as a blueprint to calibrate the use of moving simulators. In summary, the different properties of the simulator can lead drivers to react to warnings differently.
\end{abstract}

Keywords: Braking reaction time, compliance rates, fixed driving simulator, moving driving simulator, speed profiles

\section{Introduction}

Driving simulators have been used in evaluating the relative effectiveness of an enhanced road marking system $[1,2]$; risk of traffic crashes [3-5]; speeding countermeasures [6]; phone use while driving [7]; and eye fixation durations[8]. However, there are no studies that directly compare fixed and moving driving simulators in assessing safety devices at railway crossings. In the work reported here, the driver behavior at railway crossings equipped with either typical stop signs or in-vehicle audio safety systems were compared using two types of simulators (fixed and moving).

In general, fixed and moving simulators are two major types of driving simulators. Several studies have addressed the validity of different types of driving simulators [1, 3, 5, 8-12]. In a study that compared fixed and moving driving simulators, a similarity in different

\footnotetext{
* Corresponding author. Tel.: (801) 863-8373

E-mail:kshaaban@uvu.edu

(C) 2021 International Association for Sharing Knowledge and Sustainability. 
defensive reactions such as lower speed, smaller distance to the road shoulder, and a large gap to the front vehicle was found [9]. Intuitively, The more a driving simulator mimics actual physical conditions, the more the outcomes produced can be counted on [13]. For this reason, a moving driving simulator may result in better traffic measurements [6].

A range of measures related to the vehicle's pedals was studied. The braking reaction time (BRT) is of interest for rail level crossings. The BRT is defined as the time elapsed from the moment a stimulus appears until the driver presses the brake pedal[14]. It is considered safe if braking occurs within 2 seconds of the onset of a stimulus when driving at highway speeds (around $80 \mathrm{~km} / \mathrm{h}$ ) [15, 16]. Such values depend on many other factors, such as the distance to the obstacle requiring braking [17]. It is of interest to assess whether the different interventions improve BRT when compared to conventional crossings.

Other measures of interest are the time and distance to the crossing when the driver starts releasing the accelerator pedal [17-19]. Such measures are common practice in both simulated and on-road experiments. They are often measured with a video camera positioned above the driver's feet [20]. When using a driving simulator, such values can be inferred from the values of the pressure on both accelerator and brake pedals.

There have been no studies directly comparing fixed and moving driving simulators in assessing safety devices at railway crossings. In the work reported here, the results of driving behaviors at railway crossings equipped with either typical stop signs or in-vehicle audio safety system using a fixed and a moving simulator were compared. Two separate groups were recruited to participate in experiments. While one group was tested in the fixed driving simulator, the other one was conducted in the moving simulator.

In this study, three indicators including speed profiles, compliance rates, and braking reaction times were directly compared between the fixed and the moving driving simulator. This paper is an extended version of our previous work Inhi et al. [21]. The newly added material mostly expands the comparison to include compliance rates and braking distance.

The two simulators were used in the scenario of active and passive crossings. The active crossing was represented by in-vehicle audio system while the passive crossing was shown as a stop sign at the railway crossing. Other measures of interest are the time and distance to calculate speeds to approach the crossings when the driver starts releasing the accelerator pedal [17-19]. Such measures are common practice in both simulated and on-road experiments. They are often measured with a video camera positioned above the driver's feet [20].

Data used in this study were collected from two separate projects funded by the CRC for Rail Innovation. Both projects tried to investigate railway safety but one used a fixed driving simulator [22] and the other did a moving simulator [23].

\section{Experimental Design}

Two separate groups were recruited to participate in experiments. While one group used the fixed driving simulator, the other used the moving simulator. Three indicators including the compliance rate, speed profiles, and BRT were directly compared between the two types of simulators.

\subsection{Participants}

For the fixed simulator, 24 volunteers ranging in age from 17 to 66 years were recruited. All participants had a normal or corrected-to-normal vision and a current driver's license. This simulator test was performed at the research lab at the University of Queensland. For the moving simulator, although 58 drivers with ages ranging from 19 to 59 years were recruited for the whole project, only twenty participants were selected for this specific study to ensure different characteristics within the sample. This simulator test was performed at the Centre for Accident Research and Road Safety, Queensland University of Technology. More information regarding the participants can be found in the preliminary work of the authors [21, 24].

\subsection{Apparatus}

\section{Fixed simulator}

The first part of the experiment was conducted in a fixedbase driving simulator. The simulator comprised a workstation running custom software, an overhead CRT projector, a force-feedback steering wheel, an accelerator, and a brake pedal. The steering wheel produced a return force proportional to its deflection from $0^{\circ}$, equivalent to that produced in a small family car [25]. Threedimensional images were projected onto a $3.2 \mathrm{~m} \mathrm{x} 2.7 \mathrm{~m}$ white flat projection screen at a distance of $2 \mathrm{~m}$ from the 'driving seat'. A controlled computer acquired foot pedal and steering-wheel data at each frame. The layout of the fixed simulator is shown in Fig. 1.

\section{Moving simulator}

The second part of the experiment was conducted using an advanced moving driving simulator. This simulator comprised a complete automatic Holden Commodore vehicle with working controls and instruments. This advanced driving simulator uses $\mathrm{SCANeR}^{\mathrm{TM}_{\text {Studio }}}$ software with eight computers, projectors, and six degrees of freedom (6DOF) motion platform that can move and twist in three dimensions.

When seated in the simulator vehicle, the driver is immersed in a virtual environment which includes a 180degree front field of view composed of three screens, 
simulated rearview mirror images on LCD screens, surround sound for the engine and environmental noise, real car cabin, and simulated vehicle motion. The road and environment were developed to reflect the Australian Standards at railway crossings and to create realistic traffic around the driven car. The participant sits in the driver's seat of the car where he/she can see three screens on which the SCANeR ${ }^{\mathrm{TM}}$ simulation is played by three RGB video projectors. The participant drives the simulator with two pedals (brake and accelerator only) and a steering wheel that provides force feedback. The simulator is shown in Fig. 1.

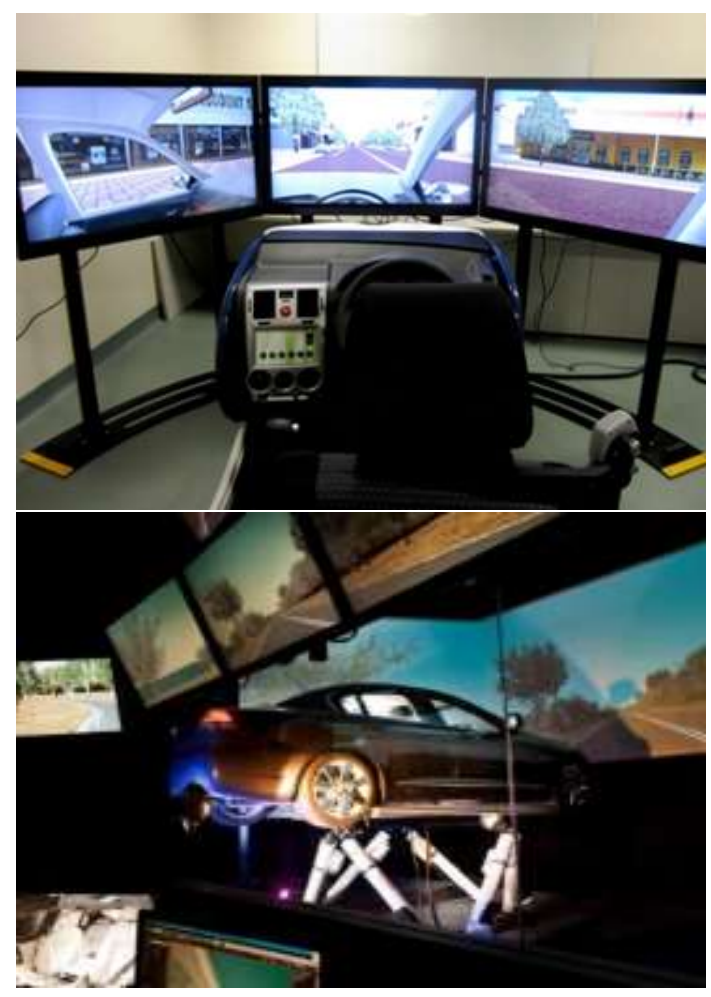

Fig. 1. Fixed Driving Simulator (Up) and Moving Driving Simulator (Down) [21]

\subsection{Development of Simulated Driving Task Environment}

A virtual environment simulation was developed. Once the start button was pressed and the accelerator pedal activated, the participant was required to 'drive' in the left-hand lane of a simulated two-lane two-way road at a preset maximum speed by manipulating the steering wheel. Participants had the visual impression of driving along a curved road. A digital speedometer on the bottom center of the display screen showed the vehicle's headlong speed. Fig. 2 provides a schematic illustration of the simulated roadway.

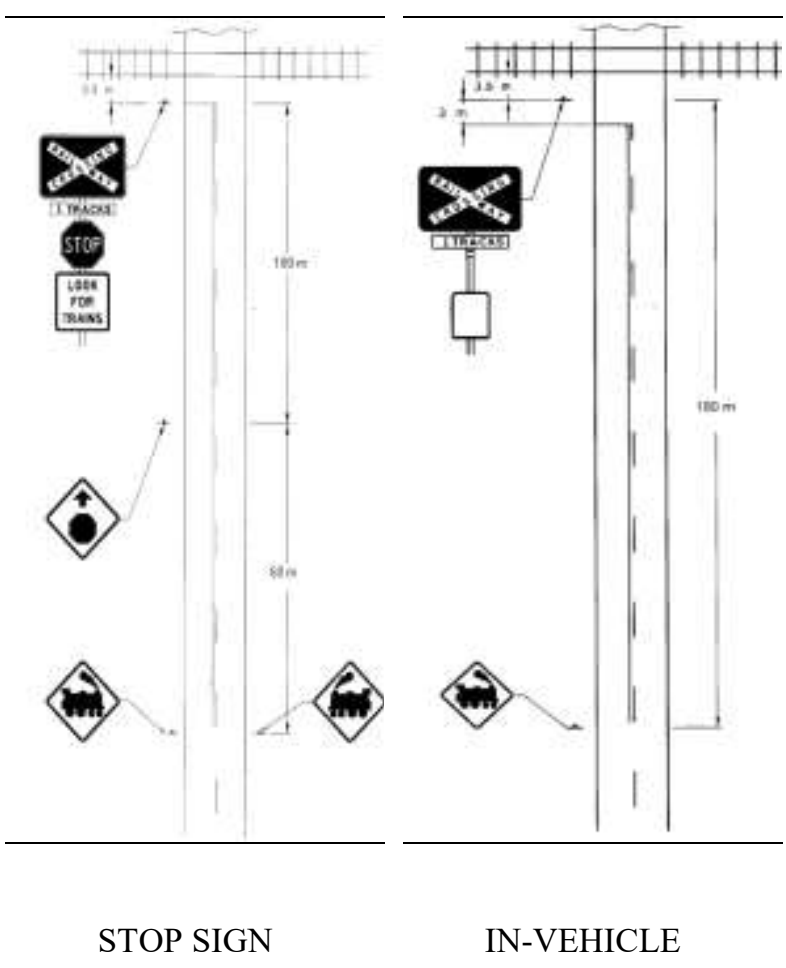

Fig. 2. Typical schematic illustration of the simulated roadway [24]

The distances pertaining to the level crossing layout and warning sign placement, are based on design specifications contained in the Manual of Uniform Traffic Control Devices, Part 7: Railway Crossings [26]. About $1.0 \mathrm{~km}$ from the start, the driver approached a level crossing. All level crossings that drivers encountered during the scenarios had the same road characteristics as shown in Table 1, with two different types of warning devices appearing randomly at the crossings. The conventional warning device (stop sign) was included as the control for the in-vehicle audio warning. A stop sign was the passive device while the in-vehicle audio warning was activated by train presence at least 21 seconds before the arrival of a train at a single-track crossing, as required by the Australian Standards.

\subsection{Safety Devices (in-vehicle audio warning)}

The audio in-vehicle system used the speakers of both simulators to provide warning messages to the driver. This in-vehicle audio safety system was fully implemented within the simulator. As a train approached the crossing, the speakers provided a verbal warning.

In this situation (train approaching), two messages were given to the driver as in the in-vehicle audio safety system presented before. The in-vehicle audio-warning triggered verbal warnings: 
Table 1. Road and Crossing Characteristics [21]

\begin{tabular}{|c|c|c|}
\hline Characteristic & Fixed simulator & Moving simulator \\
\hline Road type & $\begin{array}{l}\text { Two-lane two-way } \\
\text { sealed pavement } \\
\text { road in a rural } \\
\text { setting }\end{array}$ & $\begin{array}{l}\text { Two-lane two-way } \\
\text { sealed pavement } \\
\text { road in a rural } \\
\text { setting }\end{array}$ \\
\hline $\begin{array}{c}\text { Number of train } \\
\text { tracks }\end{array}$ & One & One \\
\hline $\begin{array}{c}\text { Horizontal } \\
\text { alignment of road }\end{array}$ & $\begin{array}{c}\text { Straight road } \\
\text { approaching level }\end{array}$ & $\begin{array}{c}\text { Straight road } \\
\text { approaching level }\end{array}$ \\
\hline $\begin{array}{l}\text { Vertical alignment } \\
\text { of road }\end{array}$ & Level & Level \\
\hline Road length & $1.0 \mathrm{~km}$ & $13 \mathrm{~km}$ (total length) \\
\hline Lane width & $3.5 \mathrm{~m}$ & $3.5 \mathrm{~m}$ \\
\hline Vehicle & $\begin{array}{c}\text { No other vehicle on } \\
\text { the road }\end{array}$ & Vehicles on the road \\
\hline Road speed limits & $\begin{array}{c}\text { Constant at either } 60 \\
\mathrm{~km} / \mathrm{h} \text { or } 80 \mathrm{~km} / \mathrm{h}\end{array}$ & $\begin{array}{c}\text { Constant at either } 60 \\
\mathrm{~km} / \mathrm{h} \text { or } 80 \mathrm{~km} / \mathrm{h}\end{array}$ \\
\hline Train speed & $50 \sim 60 \mathrm{~km} / \mathrm{h}$ & $60 \mathrm{~km} / \mathrm{h}$ \\
\hline Train length & 3 cars x $69.5 \mathrm{~m} / \mathrm{car}$ & $160 \mathrm{~m}$ \\
\hline Rail-road angle & $90^{\circ}$ & $90^{\circ}$ \\
\hline
\end{tabular}

Fixed Simulator

The in-vehicle audio-warning triggered verbal warnings:

- "Warning! Train approaching!" (21 seconds prior to a train arriving at the crossing)

- "Train crossing! Stop at the stop line" (nearby stop line)

- "Train departed. Please proceed" (the train had cleared the crossing)

\section{Moving Simulator}

In this situation (train approaching), two messages were given to the driver as in the in-vehicle audio safety system presented before:

- "Train approaching the crossing ahead"

- "Stop at the crossing".

This in-vehicle audio safety system was fully implemented with the simulator.

\section{Results}

\subsection{Speed Profiles}

This study evaluated the difference in speed at the following distances to the crossing:

- For the stop sign: 80, 50, and 20 meters away from the crossing (in distance).

- For the in-vehicle audio safety system: 2, 3, and 4 seconds after warning started (in time).

The first null hypothesis tested was:
$H_{\mathrm{o}}=$ there is no significant difference in speed profiles (in meters) between the two driving simulators in the case of stop signs only.

The second null hypothesis tested was:

$H_{\mathrm{o}}=$ there is no significant difference in speed profiles (in seconds) between the two driving simulators in the case of in-vehicle audio safety system.

Two-sample t-test analyses were performed to highlight the effects of the two different driving simulators on the speed at various distances. The results are summarized in Tables 2 and 3.

\section{Stop Sign}

The statistical t-test showed that there was no difference between the fixed and the moving simulators for distances of $80 \mathrm{~m}, 50 \mathrm{~m}$, and $20 \mathrm{~m}$ away from the crossing. The only exception appeared in the case where there was no train, and the vehicle was close to the stop line, for example, less than $20 \mathrm{~m}$ away from the crossing $(t$-test $=-3.31$, $d f=81, p=.010)$.

Table 2. Stop Sign Statistical Analysis [21]

\begin{tabular}{ccccccccc}
\hline $\begin{array}{c}\text { Distance } \\
\text { from } \\
\text { Crossing }\end{array}$ & Train & Simulator & Mean & SD & SEM & $\begin{array}{c}t- \\
\text { test }\end{array}$ & $d f$ & $\begin{array}{c}p \text { - } \\
\text { value }\end{array}$ \\
\hline \multirow{2}{*}{$80 \mathrm{~m}$} & Yes & S-1 & 51.9 & 9.1 & 1.2 & - & 83 & 0.582 \\
& & S-2 & 52.9 & 8.9 & 1.4 & 0.55 & & \\
& No & S-1 & 52 & 8.2 & 1.1 & - & 73 & 0.359 \\
& & S-2 & 53.8 & 9.9 & 1.6 & 0.92 & & \\
$50 \mathrm{~m}$ & Yes & S-1 & 46 & 11.4 & 1.5 & 0.29 & 90 & 0.772 \\
& & S-2 & 45.4 & 9.8 & 1.5 & & & \\
& & S-1 & 45.7 & 11.6 & 1.5 & - & 92 & 0.985 \\
& & S-2 & 45.8 & 9.7 & 1.5 & 0.02 & & \\
& Yes & S-1 & 30.9 & 15.6 & 2.1 & - & 93 & 0.145 \\
& & S-2 & 26.7 & 11.9 & 1.9 & 1.47 & & \\
& No & S-1 & 33.1 & 16.5 & 2.2 & - & 81 & $\underline{0.01}$ \\
& & S-2 & 24.9 & 7.1 & 1.1 & 3.31 & & \\
\hline \hline
\end{tabular}

*: $S$-1: fixed simulator, $S$-2: moving simulator

In-vehicle Audio Safety System

The vehicle speeds were extracted two, three, and five seconds after the audio warning started. This method finds whether reaction times to warnings are different. As shown in Table 3, the speeds differed between the two simulators two and three seconds after the warning started regardless of train presence. Four seconds after the audio warning started, drivers showed similar speeds for both simulators. As Table 3 shows, the speeds at a certain time after the warning started for the fixed simulator were, in general, higher than those for the moving simulator. 
Table 3. In-Vehicle Audio Warning Statistical Analysis [21]

\begin{tabular}{|c|c|c|c|c|c|c|c|c|}
\hline $\begin{array}{l}\text { Time } \\
(\mathrm{Sec})\end{array}$ & Train & Simulator & Mean & SD & SEM & $\begin{array}{c}t- \\
\text { test }\end{array}$ & $d f$ & $\begin{array}{c}p- \\
\text { value }\end{array}$ \\
\hline \multirow{4}{*}{2} & \multirow[t]{2}{*}{ Yes } & S-1 & 57.38 & 4.9 & 0.7 & \multirow{2}{*}{2.8} & \multirow{2}{*}{22} & \multirow{2}{*}{$\underline{0.01}$} \\
\hline & & S-2 & 51.39 & 9.12 & 2 & & & \\
\hline & \multirow{2}{*}{ No } & S-1 & 58.17 & 4.07 & 0.5 & \multirow[t]{2}{*}{2.62} & \multirow[t]{2}{*}{22} & \multirow{2}{*}{$\underline{0.016}$} \\
\hline & & S-2 & 53.3 & 7.96 & 1.8 & & & \\
\hline \multirow{4}{*}{3} & \multirow[t]{2}{*}{ Yes } & S-1 & 56.44 & 5.9 & 0.8 & \multirow{2}{*}{3.98} & \multirow{2}{*}{20} & \multirow{2}{*}{$\underline{0.001}$} \\
\hline & & S-2 & 46.2 & 10.4 & 2.5 & & & \\
\hline & \multirow{2}{*}{ No } & S-1 & 57.28 & 4.88 & 0.7 & \multirow{2}{*}{2.97} & \multirow{2}{*}{17} & \multirow{2}{*}{0.009} \\
\hline & & S-2 & 45.8 & 16.2 & 3.8 & & & \\
\hline \multirow{4}{*}{4} & \multirow[t]{2}{*}{ Yes } & S-1 & 54.53 & 7.79 & 1 & - & \multirow[t]{2}{*}{24} & \multirow[t]{2}{*}{0.239} \\
\hline & & S-2 & 51.54 & 9.56 & 2.3 & 1.21 & & \\
\hline & \multirow[t]{2}{*}{ No } & S-1 & 55.87 & 6.07 & 0.8 & - & \multirow[t]{2}{*}{19} & \multirow[t]{2}{*}{0.41} \\
\hline & & S-2 & 53.92 & 8.68 & 2.2 & 0.84 & & \\
\hline
\end{tabular}

$S$-1: fixed simulator, $S$-2: moving simulator

\subsection{Compliance Rates}

The following behaviors were observed from the group with the in-vehicle audio safety system while approaching passive crossings:

- The driver stopped completely at the stop line (complied).

- The driver came close to a complete stop at the stop line but did not stop completely (did not comply).

- The driver did not stop at all (did not comply).

Fig. 3 shows compliance percentages for the two different types of warning devices in both the fixed and moving simulators with an approaching speed of $60 \mathrm{~km} / \mathrm{h}$. Drivers approaching a crossing equipped with a stop sign are required to stop at the stop line and look to check if they can see a train approaching. The driver responded in one of three ways; stopped, slowed down, and did not stop. 'Stop' is considered compliant while 'slowdown' and 'did not stop' are regarded as non-compliance behavior.

Seventy-four percent of drivers in the fixed simulator completely stopped in compliance with the traffic rule; while more drivers $(80 \%)$ in the moving simulator did so. In the non-compliance categories, 16 percent and 10 percent of drivers attempted to slow down in the fixed and moving simulators, respectively. About 10 percent of drivers in both simulators drove through without slowing down or stopping.

Drivers approaching a crossing equipped with an invehicle audio warning were expected to slow down when they heard the warnings and to stop behind the stop line at the crossing. It was shown that drivers in both simulators obeyed the traffic rule.

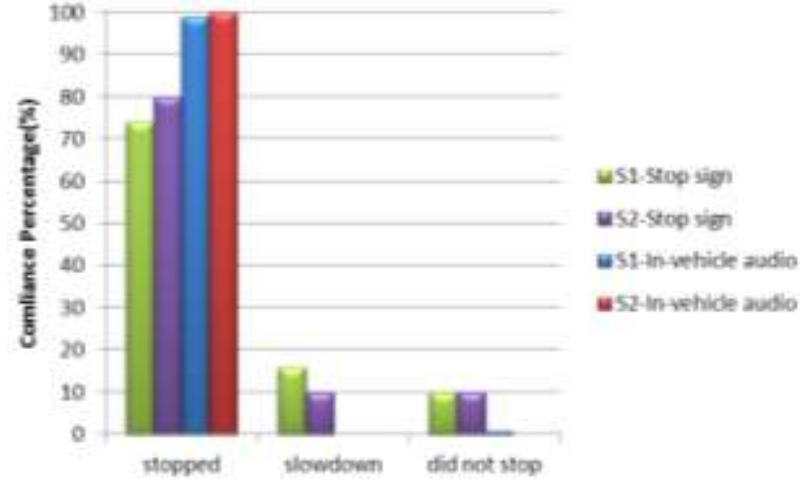

S1: fixed simulator, S2: moving simulator

Fig. 3. Compliance Rate Comparison

\subsection{Braking Reaction Times}

The braking force (or brake pressure) was also investigated. It is an accepted method in which to investigate the urgency with which the driver reacts to a situation [17]. Therefore, this measure provides another assessment of the safety of the conventional protections at railway crossings as well as the benefits or drawbacks of in-vehicle audio safety system interventions. As there were two experimental conditions and different participants were used in each condition, the independent t-test was used (Table 4).

Table 4. Independent T-Test on Braking Reaction Time

\begin{tabular}{ccccccccc}
\hline \hline & $\begin{array}{c}\text { T- } \\
\text { test }\end{array}$ & $d f$ & $p$ & Mean & SD & SEM & $\begin{array}{c}\text { 95\% Confidence Interval } \\
\text { of the Difference }\end{array}$ \\
& & & & & & & Lower & Upper \\
\hline S-1 & 13.7 & 47 & .000 & 3.26 & 1.65 & .24 & 2.8 & 3.7 \\
S-2 & 20.4 & 32 & .000 & 2.30 & .65 & .11 & 2.1 & 2.5 \\
\hline \hline
\end{tabular}

The null hypothesis tested was:

$H_{\mathrm{o}}=$ there is no significant difference in braking reaction time in second between two driving simulators equipped with in-vehicle audio safety system.

BRTs from both simulators in the case of in-vehicle audio warning were compared. As Fig. 4 shows, drivers in the moving simulator took a shorter time (mean=2.30, $t=13.7, d f=47, p<.001)$ than those in the fixed simulator (mean $=3.26, t=20.4, d f=32, p<.001$ ). The variation of BRT is also smaller $(\mathrm{SD}=0.65)$ in the driving simulator than in the fixed simulator $(\mathrm{SD}=1.65)$. 


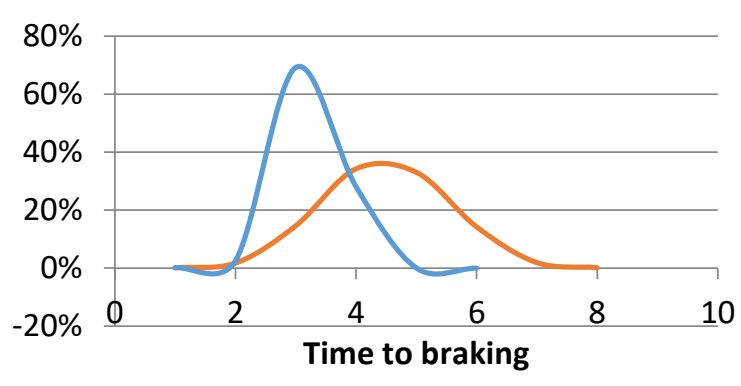

_Fixed simulator

\section{Fig. 4. Distributions of BRT}

Fig. 4 shows that drivers from the two simulators had different BRTs with significantly different variations. The BRT of the fixed simulator indicates a larger mean with a larger standard deviation, which means drivers generally were slower in responding to warnings. On the other hand, the BRT of the moving simulator was clustered closely around the mean, indicating that drivers paid more attention to the warnings.

\section{Conclusion}

In this study, fixed and moving simulators were used to evaluate speeds, compliance rates, and braking reaction times for drivers near or at a railway crossing. Initially, two separate projects were performed to identify the effectiveness of new safety devices using both fixed and moving simulators. Since both studies involved an invehicle safety device and a stop sign as a base case, the authors tried to analyze how these two simulators are different from each other.

The speeds at a given distance (for stop sign) or time (for in-vehicle audio safety system) were compared. Drivers approaching the crossing with a stop sign slowed down in a similar pattern in both driving simulators when a train was about to intersect. However, when the railway crossing was controlled with in-vehicle audio warnings, the drivers' behavior was different. Drivers in the fixed simulator tended to react slower than those in the moving simulator and the results were statistically different. However, after a few seconds (here, 4 seconds) of warning, the speed distributions from the two simulators were not statistically different regardless of the train's existence. It was found that the driving trajectories were influenced by the characteristics of the driving simulators immediately after the warnings started.

There was no significant difference in the way drivers responded in terms of compliance rate. Although drivers complied slightly more in the fixed simulator at a stop sign, they behaved almost identically on both simulators in relation to the in-vehicle audio warning. In the case of drivers approaching a crossing equipped with a stop sign, they are required to stop at the stop line to check for a train approaching. Drivers respond in one of three ways; stopped, slowed down, or did not stop. 'Stop' is considered compliant while 'slowdown' and 'did not stop' are regarded as non-compliance behavior.

From the study conducted by Tey [27], the compliance rates in the fixed simulator were higher than those measured in the field by approximately 30 percent. This is because the fixed simulator is not able to include some factors such as fatigue, the ability to maintain attention, traffic conditions, and adequate noise that may occur in the field. However, the patterns in speed profiles from the simulators were found to be consistent with the field results.

Since braking reaction time is an accepted method in which to investigate the urgency with which the driver reacts to a situation [17], this measure provides another assessment of the safety of the conventional protections at railway crossings as well as the benefits or drawbacks of in-vehicle audio safety system interventions. Braking reaction times to the warning were also different for the two simulators. Drivers in the moving simulator reacted relatively faster. Additionally, drivers in the fixed simulator showed great variation in their reaction times, whereas drivers had similar reaction times in the moving simulator. This different environment leads drivers to react to warnings differently.

\section{References}

[1] T. Horberry, J. Anderson, and M. A. Regan, "The possible safety benefits of enhanced road markings: A driving simulator evaluation," Transportation Research Part F: Traffic Psychology and Behaviour, vol. 9, no. 1, pp. 77-87, 2006, doi: http://dx.doi.org/10.1016/j.trf.2005.09.002.

[2] Q. Hussain, W. K. Alhajyaseen, A. Pirdavani, K. Brijs, K. Shaaban, and T. Brijs, "Do detection-based warning strategies improve vehicle yielding behavior at uncontrolled midblock crosswalks?," Accident Analysis \& Prevention, vol. 157, p. 106166, 2021.

[3] X. Yan, M. Abdel-Aty, E. Radwan, X. Wang, and P. Chilakapati, "Validating a driving simulator using surrogate safety measures," Accident Analysis and Prevention, vol. 40, no. 1, p. 274, 2008.

[4] M. Abdel-Aty, X. Yan, E. Radwan, and X. Wang, "Using drivers' stop/go decisions in driving simulator to assess rear-end crash risk at signalized intersections," Journal of Transportation Safety \& Security, vol. 1, no. 2, pp. 85-100, 2009.

[5] R. W. Allen, G. D. Park, and M. L. Cook, "Simulator Fidelity and Validity in a Transfer-of-Training Context," Transportation Research Record: Journal 
of the Transportation Research Board, vol. 2185, no. -1, pp. 40-47, 2010.

[6] S. T. Godley, T. J. Triggs, and B. N. Fildes, "Driving simulator validation for speed research," Accident Analysis \& Prevention, vol. 34, no. 5, pp. 589-600, 2002, doi: http://dx.doi.org/10.1016/S00014575(01)00056-2.

[7] P. Matthew and P. A. Green, "Comparison of driving performance on-road and in a low-cost simulator using a concurrent telephone dialling task," Ergonomics, vol. 42, no. 8, pp. 1015-1037, 1999.

[8] G. Underwood, D. Crundall, and P. Chapman, "Driving simulator validation with hazard perception," Transportation Research Part F: Traffic Psychology and Behaviour, vol. 14, no. 6, pp. 435-446, 2011, doi: http://dx.doi.org/10.1016/j.trf.2011.04.008.

[9] J. Santos, N. Merat, S. Mouta, K. Brookhuis, and D. de Waard, "The interaction between driving and invehicle information systems: Comparison of results from laboratory, simulator and real-world studies," Transportation Research Part F: Traffic Psychology and Behaviour, vol. 8, no. 2, pp. 135-146, 2005, doi: http://dx.doi.org/10.1016/j.trf.2005.04.001.

[10] C. Ho, N. Reed, and C. Spence, "Assessing the effectiveness of "intuitive" vibrotactile warning signals in preventing front-to-rear-end collisions in a driving simulator," Accident Analysis \& Prevention, vol. 38, no. 5, pp. 988-996, 2006, doi: http://dx.doi.org/10.1016/j.aap.2006.04.002.

[11] B. Lewis-Evans and S. G. Charlton, "Explicit and implicit processes in behavioural adaptation to road width," Accident Analysis \& Prevention, vol. 38, no. 3, pp. 610-617, 2006, doi: http://dx.doi.org/10.1016/j.aap.2005.12.005.

[12] P. Hofmann, G. Rinkenauer, and D. Gude, "Preparing lane changes while driving in a fixedbase simulator: Effects of advance information about direction and amplitude on reaction time and steering kinematics," Transportation Research Part F: Traffic Psychology and Behaviour, vol. 13, no. 4, pp. 255-268, 2010, doi: http://dx.doi.org/10.1016/j.trf.2010.04.009.

[13] T. Triggs, "Some critical human factors issues and challenges in simulation and training," Simtect 96 Proceedings, pp. 21-26, 1996.

[14] D. Shinar, Traffic Safety and Human Behavior. Emerald Group Publishing Limited, 2007.
[15] C. M. Rudin-Brown and H. A. Parker, "Behavioural adaptation to adaptive cruise control (ACC): implications for preventive strategies," Transportation Research Part F: Traffic Psychology and Behaviour, vol. 7, no. 2, pp. 59-76, 2004.

[16] G. Taoka, "Break reaction times of unalerted drivers," ITE Journal, vol. 59, no. 3, pp. 19-21, 1989.

[17] C. M. Rudin-Brown, A. Williamson, and M. G. Lenné, "Can driving simulation be used to predict changes in real-world crash risk?," Monash University, 2009.

[18] M. M. Porter, P. Irani, and T. A. Mondor, "Effect of Auditory Road Safety Alerts on Brake Response Times of Younger and Older Male Drivers: A Simulator Study," Transportation Research Record: Journal of the Transportation Research Board, vol. 2069, no. 1, pp. 41-47, 2008.

[19] L.-S. Tey, L. Ferreira, and A. Wallace, "Measuring driver responses at railway level crossings," Accident Analysis \& Prevention, vol. 43, no. 6, pp. 2134-2141, 2011.

[20] C. M. Rudin-Brown and Y. Ian Noy, "Investigation of behavioral adaptation to lane departure warnings," Transportation Research Record: Journal of the Transportation Research Board, vol. 1803, no. 1, pp. 30-37, 2002.

[21] I. Kim, G. Larue, L. Ferreira, A. Rakotonirainy, and K. Shaaban, "Driver behaviors at level crossings from fixed and moving driving simulators," Procedia Computer Science, vol. 130, pp. 103-110, 2018.

[22] L. S. Tey, "Evaluating driver behaviour towards railway level crossing warning devices using simulation," Ph.D., Civil engineering, University of Queensland, 2013.

[23] G. Larue et al., "Intelligent Transport System for Safer Level Crossings," CRC for rail innovation, 2013.

[24] I. Kim, G. Larue, L. Ferreira, A. Rakotonirainy, and K. Shaaban, "Traffic Safety at Road Rail Level Crossings Using a Driving Simulator and Traffic Simulation," Transportation Research Record: Journal of the Transportation Research Board, vol. 2476, pp. 109-118, oct 2015, doi: 10.3141/2476-15.

[25] G. Wallis, A. Chatziastros, and H. Bülthoff, "An Unexpected Role for Visual Feedback in Vehicle Steering Control," Current Biology, vol. 12, no. 4, pp. 295-299, 2002. 
[26] (2009). AS 1742.7-2007, Manual of Uniform Traffic Control Devices, Part 7: Railway Crossings.

[27] L. S. Tey, "Evaluating driver behaviour towards railway level crossing warning devices using simulation," PhD, Civil Engineering, The University of Queensland, 2013. 